\title{
ORIGINAL
}

ARTICLES

\section{Prevalence, Plans, and Perceptions: Disability in Family Medicine Residencies}

Lisa M. Meeks, PhD, MA; Ben Case, MPH; Heidi Joshi, PsyD; Lisa Graves, MD, MClinSc; Diane M. Harper, MD, MPH

\begin{abstract}
BACKGROUND AND OBJECTIVES: Leading medical organizations including the Accreditation Council for Graduate Medical Education (ACGME) and American Association of Medical Colleges (AAMC) espouse the value of a diverse physician workforce, including disability, yet there is a dearth of research about this population in graduate medical education (GME). More information is needed on the prevalence of disability in the resident population, plans to recruit residents with disabilities, and program perceptions of barriers to inclusion. The goal of this study was to better understand the prevalence of disability in the resident population, plans to recruit residents with disabilities, and program perceptions of barriers to disability inclusion and frequency of disability-related complaints and litigation.
\end{abstract}

METHODS: Surveys were emailed to 200 department chairs via SurveyMonkey as part of a larger omnibus survey conducted by the Council of Academic Family Medicine Educational Research Alliance (CERA).

RESULTS: More than $30 \%$ of family medicine programs reported at least one faculty member with a disability, while $50 \%$ reported matriculating at least one resident with a disability in the previous 5 years. Programs with greater numbers of physicians with disabilities were more likely to have a plan to recruit residents with disabilities, and inadequate expertise was the largest perceived barrier to disability inclusion.

CONCLUSIONS: Employing faculty with disabilities may be the driving force for having an active plan to recruit residents with disabilities. In order to meet the stated diversity goals of medicine, programs will need to increase professional development around disability inclusion.

(Fam Med. 2021;53(5):338-46.)

doi: 10.22454/FamMed.2021.616867

A pproximately one in six individuals worldwide identifies as a person with a disability, ${ }^{1}$ defined by the Americans With Disabilities Act (ADA) as a physical or mental impairment that substantially limits a major life activity ${ }^{2}$ Many of these individuals will seek treatment by family physicians.
Developing a diverse physician workforce that mirrors the patient population is critical to providing more culturally informed care and is a stated goal of medical organizations including the Accreditation Council on Graduate Medical Education (ACGME) and the American Association of Medical Colleges (AAMC) ${ }^{3-9}$ These organizations espouse the value of a diverse physician workforce, including disability, and have developed guidance $^{7}$ and mandates ${ }^{8-10}$ for increasing diversity, setting disability policy expectations, and for accommodating disabled learners. As such, disability inclusion in residency has become an increasingly important topic.

Despite stated commitments to disability inclusion, there exist few studies on the topic or prevalence of disabled learners in graduate medical education (GME). One Council of Academic Family Medicine Educational Research Alliance (CERA) study focused on faculty with disabilities, showing that almost half (41.9\%) of family medicine chairs reported employing a faculty member with a disability. ${ }^{11}$ The prevalence of residents with disabilities (RWD) is poorly studied, with only a few articles on the topic to date. A 2002 study $^{12}$ found that $1.3 \%$ of emergency medicine programs reported learners with disabilities, and found that programs with disabled residents were significantly more

From the University of Michigan Medical School, Ann Arbor, MI (Drs Meeks and Harper, and Mr Case); Center for a Diverse Healthcare Workforce, University of California, Davis, School of Medicine, Sacramento, CA (Dr Meeks) John Muir Family Medicine Residency, Walnut Creek, CA (Dr Joshi); and Western Michigan University Homer Stryker M.D. School of Medicine, Kalamazoo, MI (Dr Graves). 
likely to report having resources for assisting these learners.

A more recent study of emergency medicine residents conducted after the ADA Amendments Act, where the definitions of major life activity were expanded to include impairments in concentration and other activities ${ }^{13}$ showed that $26 \%$ of programs report having a resident with a disability, for a total prevalence of 4.06\%. ${ }^{14}$ Additionally, this study suggested that residency programs with disabled residents were more likely to have disability education in their training and that program directors reported more confidence in developing workplace accommodations for physical, psychological, and chronic health disabilities. ${ }^{14}$ While GME data on specific prevalence is lacking, a recent publication highlights GME's general lack of compliance with the ACGME's requirement to maintain a disability-related policy for residents and house staff. ${ }^{15}$

While there is a dearth of research on disability prevalence in GME, studies in undergraduate medical education (UME) have successfully measured the growth of this population over time, demonstrating that approximately $4.6 \%$ of learners in allopathic programs ${ }^{16,17}$ and $4.27 \%$ of learners in osteopathic programs ${ }^{18}$ disclose a disability. These learners will soon transition to GME, including family medicine residencies. Collecting data on the prevalence of residents with disabilities would provide the first comprehensive understanding of the medical education pathway from UME to GME and into practice in family medicine. Furthermore, in light of the new ACGME requirements for disability policy, ${ }^{9}$ accommodations for residents with disabilities ${ }^{10}$ and stated commitments to diversity including disability, ${ }^{8}$ a better understanding of disability in the resident population, and residency programs is needed.

As part of a larger CERA study subsection of questions on disability in family medicine, we sought to (1) identify the prevalence of faculty with disability and residents with disabilities in family medicine programs over the last 5 years, (2) identify program chairs' perceptions of barriers to disability inclusion, (3) assess active plans to recruit residents with disabilities into family medicine programs, (4) assess the availability of training on the topic of working with residents with disabilities, and (5) identify the number of programs that have experienced disability-related institutional complaints or litigation.

\section{Methods}

The survey questions were part of a larger omnibus survey conducted by CERA. The survey was conducted utilizing the standard CERA survey methodology..$^{19}$ There were 55 questions in the survey, of which 10 questions were a distinct investigator-initiated subproject surveying family medicine residency programs and disability. A set of 11 demographic questions common to all subprojects were included. Pretesting was done on family medicine educators who were not part of the target population. Questions were modified following pretesting for flow, timing, and readability. The American Academy of Family Physicians Institutional Review Board approved the project in August 2019.

Data were collected from August 2019 to October 2019. The sampling frame for the survey was US Family Medicine department chairs as identified by the Association of Departments of Family Medicine. Surveys were emailed to 200 department chairs via Survey Monkey. One email was out of date, and six participants opted out. We sent four reminders to nonresponders. Two respondents completed only two of the 55 total questions and were dropped from the analysis. The final sample size for department chairs was 191.

All data variables were categorical except for the number of years the respondent has currently served as chair, and the number of full-time equivalents (FTEs) in their department. We used IBM SPSS Statistics Version 26 software to perform the data analysis for this study. We completed descriptive statistics for the common demographic questions and all of the residency program and disability practices questions. To improve our ability to test for associations, we dichotomized variables. We assessed associations between the reported disability practices of residency programs and the demographics of respondents using $\chi^{2}$ tests for categorical variables. Fisher exact tests were used if cell sizes of less than five were present with odds ratios reported as a measure of independence. To assess associations between a continuous variable with categorical variables, we used oneway analyses of variance with Tukey honest significant difference post hoc comparisons. We ran all analyses at a two-sided $\alpha=0.05$ significance level.

\section{Results}

Respondent Demographics and Department Characteristics

The survey response rate was $53.9 \%$ (103/191). Some survey respondents did not complete all questions. Table 1 lists the demographic characteristics of the department chairs. We dichotomized residency program type to condense the community-based programs into one category, and dropped the remaining categories. We collapsed the residency program location into Region 1 and Region 2 to dichotomize the study population into an approximate half-and-half comparison in order to power some of the statistical analyses. Community size was dichotomized to "rural" as less than 75,000, and "urban" as 75,000 or more, as defined by the larger omnibus CERA survey categorization.

\section{Residency Program and Disability Practices}

Table 2 shows the frequencies of the responses to the residency program and disability questions and the dichotomized variables for number of RWD; number of faculty with disabilities (FWD); active plan to recruit RWD; and the biggest perceived barrier to inclusion of RWD. 
Table 1: Descriptive Statistics of Family Medicine Chairs

\begin{tabular}{|c|c|c|c|}
\hline \multicolumn{3}{|c|}{ Variables } & n (\%) \\
\hline \multicolumn{3}{|c|}{ Type of Residency Program } & Respondents $=102$ \\
\hline \multicolumn{3}{|l|}{ Medical school based } & $45(44.1)$ \\
\hline \multicolumn{3}{|c|}{ Community based, medical school affiliated } & $23(22.6)$ \\
\hline \multicolumn{3}{|c|}{ Community based, medical school administered } & $15(14.7)$ \\
\hline \multicolumn{3}{|c|}{ Community based, nonaffiliated } & $2(2)$ \\
\hline \multicolumn{3}{|l|}{ Other } & $3(2.9)$ \\
\hline \multicolumn{3}{|l|}{ Don't have a residency } & $14(13.7)$ \\
\hline \multicolumn{3}{|l|}{ No response } & 1 \\
\hline \multicolumn{3}{|c|}{ Type of Residency Program (Dichotomous) } & Respondents $=85$ \\
\hline \multicolumn{3}{|l|}{ Medical school based } & $45(52.9)$ \\
\hline \multicolumn{3}{|c|}{ Community based (includes medical school-affiliated, -administered, nonaffiliated) } & $40(47.1)$ \\
\hline \multicolumn{3}{|c|}{ Location of Residency (State) } & Respondents $=103$ \\
\hline \multicolumn{3}{|c|}{ New England (NH, MA, ME, VT, RI, or CT) } & $6(5.8)$ \\
\hline \multicolumn{3}{|c|}{ Middle Atlantic (NY, PA, or NJ) } & $13(12.6)$ \\
\hline \multicolumn{3}{|c|}{ South Atlantic (PR, FL, GA, SC, NC, VA, DC, WV, DE, or MD) } & $27(26.2)$ \\
\hline \multicolumn{3}{|c|}{ East South Central (KY, TN, MS, or AL) } & $6(5.8)$ \\
\hline \multicolumn{3}{|c|}{ East North Central (WI, MI, OH, IN, or IL) } & $17(16.5)$ \\
\hline \multicolumn{3}{|c|}{ West South Central (OK, AR, LA, or TX) } & $10(9.7)$ \\
\hline \multicolumn{3}{|c|}{ West North Central (ND, MN, SD, IA, NE, KS, or MO) } & $9(8.8)$ \\
\hline \multicolumn{3}{|c|}{ Mountain (MT, ID, WY, NV, UT, AZ, CO, or NM) } & $8(7.8)$ \\
\hline \multicolumn{3}{|c|}{ Pacific (WA, OR, CA, AK, or HI) } & $7(6.8)$ \\
\hline \multicolumn{3}{|c|}{ Location of Residency (Dichotomous) } & Respondents $=103$ \\
\hline \multicolumn{3}{|c|}{ Region 1 (New England, Middle Atlantic, East North Central, West North Central, Pacific) } & $52(50.5)$ \\
\hline \multicolumn{3}{|c|}{ Region 2 (South Atlantic, East South Central, West South Central, Mountain) } & $51(49.5)$ \\
\hline Variables & n (\%) & Variables & n (\%) \\
\hline Community Size & Respondents $=98$ & Community Size (Dichotomous) & Respondents $=98$ \\
\hline Less than 30,000 & $5(5.1)$ & \multirow{3}{*}{ Rural $(<75,000)$} & \multirow{3}{*}{$15(15.3)$} \\
\hline 30,000 to 74,999 & $10(10.2)$ & & \\
\hline 75,000 to 149,000 & $15(15.3)$ & & \\
\hline 150,000 to 499,999 & $26(26.5)$ & \multirow{4}{*}{ Urban $(>75,000)$} & \\
\hline 500,000 to 1 million & $16(16.4)$ & & $82(817)$ \\
\hline More than 1 million & $26(26.5)$ & & $00(04.1)$ \\
\hline No Response & 5 & & \\
\hline Gender & Respondents $=99$ & Ethnicity & Respondents $=93$ \\
\hline Male & $35(35.4)$ & Hispanic/Latino & $2(2.2)$ \\
\hline Female & $61(61.6)$ & Non-Hispanic/Latino & $91(97.8)$ \\
\hline Choose not to disclose & $3(3)$ & No roanonas & 10 \\
\hline No response & 4 & No response & 10 \\
\hline
\end{tabular}


Table 1: Continued

\begin{tabular}{|c|c|c|c|c|c|}
\hline Race & Respondents $=98$ & \multicolumn{2}{|c|}{ Age } & \multicolumn{2}{|c|}{ Respondents $=99$} \\
\hline American Indian or Alaska Native & $1(1.1)$ & \multicolumn{2}{|c|}{ 40-49 years } & \multicolumn{2}{|c|}{$16(16.2)$} \\
\hline Asian & $7(7.1)$ & \multicolumn{2}{|c|}{ 50-59 years } & \multicolumn{2}{|c|}{$36(36.4)$} \\
\hline Black or African American & $6(6.1)$ & \multicolumn{2}{|c|}{$60-69$ years } & \multicolumn{2}{|c|}{$44(44.4)$} \\
\hline White & $77(78.6)$ & \multicolumn{2}{|c|}{$70+$ years } & \multicolumn{2}{|c|}{$3(3)$} \\
\hline Choose not to disclose & $7(7.1)$ & \multirow{2}{*}{\multicolumn{2}{|c|}{ No response }} & \multirow{2}{*}{\multicolumn{2}{|c|}{4}} \\
\hline No response & 5 & & & & \\
\hline Variable & Respondents & Mean & Std Deviation & Min & Max \\
\hline Number of all FTEs per department & 96 & 33.46 & 38.89 & 0 & 300 \\
\hline
\end{tabular}

Abbreviation: FTE, full-time equivalent.

\section{Residents and Faculty Members With Disabilities}

Of 66 respondents, 33 (50\%) reported that they have had no RWD enter their program in the past 5 years, while $28(42.4 \%)$ reported matriculating between one and two RWD. Five programs $(7.6 \%)$ reported matriculating between three and five residents in the last 5 years, while no programs $(0 \%)$ reported more than five RWD. Of the 68 chairs who reported data on faculty members with disabilities (FWD), over half, $47(69.1 \%)$ stated they do not have FWD. Seventeen chairs (25\%) reported one FWD and four (5.9\%) reported more than one FWD.

\section{Active Recruitment for Residents With Disabilities and Faculty} Training on Disability Inclusion When asked whether the department had active plans to recruit RWD, five (7\%) chairs responded yes, $51(71.8 \%)$ said no, and 15 (21.2\%) stated that they did not know if there was a plan to recruit RWD. When asked if faculty training focused on working with residents with disabilities is available, $30(42.3 \%)$ said no, $18(25.3 \%)$ said yes, and $23(32.4 \%)$ said they did not know.

\section{Perceived Barriers to Disability} Inclusion and Litigious Activity When asked about perceived barriers to inclusion of RWD, 60 chairs responded. Of the known barriers to inclusion in GME, we hypothesized that cost or resources to support RWD would be the highest perceived barrier in family medicine. Counter to our hypothesis, the majority of chairs reported that inadequate expertise $(51.7 \%$; 95\% CI: 38\%, 64\%) was the most prevalent barrier to inclusion of RWD, with only 20 (33\%; $95 \%$ CI: $22 \%, 46 \%$ ) reporting cost or resources to support residents as a barrier. Importantly, attitudinal barriers, prior bad experience, lack of willingness from faculty and fear of patient safety together only accounted for $15 \%$ of the total perceived barriers (Table 2).

Of the 71 responses on whether they had experienced litigation or internal complaints involving RWD in the last 4 years, only two program chairs $(2.8 \%)$ said yes, while $62(87.3 \%)$ said no.

There were no significant results when $c^{2}$ and Fisher's exact tests compared the dichotomized number of RWD in the last 5 years with the number of FWD, community size, residency program type, and residency program region (Table 3 ).

Having active plans to recruit RWD by the number of FWD was significant $(P=.006)$. There were no significant results when active plans to recruit RWD was compared by community size, residency program type, and residency program region (Table 4). Despite the ACGME requirements to develop a recruitment and retention plan for greater diversity, the majority of programs did not maintain a plan specific to disability. However, programs with greater numbers of physicians with disabilities were more likely to have a plan, suggesting that having FWD may be the driving force for having an active plan to recruit RWD. The correlation between having FWD and having an active departmental plan to recruit RWD suggests that successes with FWD positively informs the decision to recruit more actively RWD.

When considering the largest barrier to inclusion of RWD, analyses included the number of FWD, community size, residency program type, and residency program region. All contingency tables and test statistics are presented in Table 5.

\section{Discussion}

Prevalence of Residents and Faculty With Disabilities

The reported $30.9 \%$ (95\% CI: $20 \%$, $43 \%$ ) prevalence of family medicine programs with at least one FWD is considerably lower than the $41.9 \%$ prevalence reported in the 2015 study. ${ }^{11}$ Alternatively, this may be due to the variation in how chairs define disability or the reporting of apparent disabilities only, to the exclusion of nonapparent disabilities, despite using the ADA definition of disability in the survey. ${ }^{2}$ Another possible explanation for the decrease in reported prevalence is that family medicine is not actively recruiting 
Table 2: Summary of Questions Related to Disability

\begin{tabular}{|c|c|c|c|}
\hline Variables & n (\%) & Variables & n (\%) \\
\hline $\begin{array}{c}\text { Number of Residents With } \\
\text { Disabilities (RWD) in Last } 5 \text { Years }\end{array}$ & Respondents $=66$ & $\begin{array}{l}\text { Number of Residents With Disabilities } \\
\text { (RWD) in Last } 5 \text { Years (Dichotomous) }\end{array}$ & Respondents $=66$ \\
\hline None & $33(50)$ & \multirow{3}{*}{ None } & \multirow{3}{*}{$33(50)$} \\
\hline 1 & $11(16.7)$ & & \\
\hline 2 & $17(25.7)$ & & \\
\hline 3 & $4(6.1)$ & \multirow{4}{*}{ One or more } & \multirow{4}{*}{$33(50)$} \\
\hline 4 to 5 & $1(1.5)$ & & \\
\hline More than 5 & $0(0)$ & & \\
\hline No response & 37 & & \\
\hline $\begin{array}{l}\text { Number of Faculty With } \\
\text { Disabilities (FWD) }\end{array}$ & Respondents $=68$ & $\begin{array}{c}\text { Number of Faculty With Disabilities } \\
\text { (FWD) (Dichotomous) }\end{array}$ & Respondents $=68$ \\
\hline None & $47(69.1)$ & \multirow{3}{*}{ None } & \multirow{3}{*}{$47(69.1)$} \\
\hline 1 & $17(25)$ & & \\
\hline 2 & $2(2.9)$ & & \\
\hline 3 & $1(1.5)$ & \multirow{4}{*}{ One or more } & \multirow{4}{*}{$21(30.9)$} \\
\hline 4 & $0(0)$ & & \\
\hline More than 5 & $1(1.5)$ & & \\
\hline No response & 35 & & \\
\hline $\begin{array}{l}\text { Active Plan to Recruit Residents } \\
\text { With Disabilities (RWD) }\end{array}$ & Respondents $=71$ & $\begin{array}{l}\text { Active Plan to Recruit Residents } \\
\text { With Disabilities (RWD)s }\end{array}$ & Respondents $=56$ \\
\hline Yes & $5(7)$ & \multirow{2}{*}{ Yes } & \multirow{2}{*}{$5(8.9)$} \\
\hline No & $51(71.8)$ & & \\
\hline I don't know & $15(21.2)$ & \multirow{2}{*}{ No } & \multirow{2}{*}{$51(91.1)$} \\
\hline No response & 32 & & \\
\hline $\begin{array}{c}\text { Biggest Barrier to } \\
\text { Inclusion of Residents With } \\
\text { Disabilities in Program } \\
\end{array}$ & Respondents $=60$ & $\begin{array}{l}\text { Biggest Barrier to Inclusion of } \\
\text { Residents With Disabilities in } \\
\text { Program (Dichotomous) }\end{array}$ & Respondents $=60$ \\
\hline Attitudinal & $4(6.7)$ & \multirow{3}{*}{$\begin{array}{l}\text { Inadequate expertise (includes: } \\
\text { attitudinal, lack of willingness from } \\
\text { faculty, prior bad experience, fear for } \\
\text { patient safety) }\end{array}$} & \multirow{3}{*}{$40(66.7)$} \\
\hline Cost/resources to support resident & $20(33.3)$ & & \\
\hline Lack of willingness from faculty & $1(1.7)$ & & \\
\hline Prior bad experience & $2(3.3)$ & \multirow{4}{*}{ Cost/resources to support resident } & \multirow{4}{*}{$20(33.3)$} \\
\hline Fear for patient safety & $2(3.3)$ & & \\
\hline Inadequate expertise & $31(51.7)$ & & \\
\hline No response & 43 & & \\
\hline \multicolumn{3}{|c|}{ Training Available to Faculty for Referring Residents to Disclose } & Respondents $=71$ \\
\hline Yes & & & $18(25.3)$ \\
\hline No & & & $30(42.3)$ \\
\hline I don't know & & & $23(32.4)$ \\
\hline No response & & & 32 \\
\hline \multicolumn{3}{|c|}{ Internal Complaints or Litigation Involving Resident With Disability in Last 4 Years } & Respondents $=71$ \\
\hline Yes & & & $2(2.8)$ \\
\hline No & & & $62(87.3)$ \\
\hline I don't know & & & $7(9.9)$ \\
\hline No response & & & 32 \\
\hline
\end{tabular}


Table 3: Number of Residents With Disabilities in Last 5 Years ( $N=66)$

\begin{tabular}{|c|c|c|c|}
\hline \multicolumn{4}{|c|}{ Number of Faculty With Disabilities } \\
\hline & No Faculty With Disabilities & $\begin{array}{l}\text { One or More Faculty } \\
\text { With Disabilities }\end{array}$ & Total \\
\hline No residents with disabilities & $25(39 \%)$ & $8(12 \%)$ & 33 \\
\hline One or more residents with disabilities & $21(32 \%)$ & $11(17 \%)$ & 32 \\
\hline Total & 46 & 19 & 65 \\
\hline$\chi^{2}$ value: 0.806 & Degrees of freedom: 1 & $P$ value $=$. & \\
\hline \multicolumn{4}{|c|}{ Community Size } \\
\hline & Urban & Rural & Total \\
\hline No residents with disabilities & $29(45 \%)$ & $3(4 \%)$ & 32 \\
\hline One or more residents with disabilities & $27(42 \%)$ & $6(9 \%)$ & 33 \\
\hline Total & 56 & 9 & 65 \\
\hline Odds ratio: 0.466 & Degrees of freedom: 1 & \multicolumn{2}{|c|}{$P$ value $=.475$} \\
\hline \multicolumn{4}{|c|}{ Residency Program Type } \\
\hline & Medical School Based & Community Based & Total \\
\hline No residents with disabilities & $20(31 \%)$ & $11(17 \%)$ & 31 \\
\hline One or more residents with disabilities & $16(25 \%)$ & $17(27 \%)$ & 33 \\
\hline Total & 36 & 28 & 64 \\
\hline$\chi^{2}$ value: 1.669 & Degrees of freedom: 1 & \multicolumn{2}{|c|}{$P$ value $=.196$} \\
\hline \multicolumn{4}{|c|}{ Residency Program Region } \\
\hline & Region 1 & Region 2 & Total \\
\hline No residents with disabilities & $15(23 \%)$ & $18(27 \%)$ & 33 \\
\hline One or more residents with disabilities & $16(24 \%)$ & $17(26 \%)$ & 33 \\
\hline Total & 31 & 35 & 66 \\
\hline$\chi^{2}$ value: 1.669 & Degrees of freedom: 1 & \multicolumn{2}{|c|}{$P$ value $=.196$} \\
\hline
\end{tabular}

* Not all respondents answered each question. We ran $\chi^{2}$ tests on cases in which the questions of the number of RWD question and the categorical variable of interest were both answered.

** The dichotomization of residency program type resulted in loss of respondents that selected a program type that was not in medical school- or community-based institution.

for disability as part of its efforts toward diversity.

It is noteworthy that out of 66 respondents, half have had residents with disabilities train in their program in the last 5 years. Just over one-quarter (25.8\%) stated their program trained two residents with disabilities in the last 5 years. This is a strong benchmark on which to observe the changes in this population in future studies.

\section{Systematic Barriers to Disability} Inclusion in GME

A correlation was found between having FWD and having an active departmental plan to recruit RWD. This has significant implications for building and maintaining a pathway from UME to GME for learners with disabilities. It may be that working alongside a physician with a disability reduces stereotypes and stigma about disability through proximation and shared goals, two tenets of intercontact theory, ${ }^{19}$ making faculty more open to the idea of training a resident with a disability.

\section{Limitations}

Our study has limitations. Although the study was distributed to all known family medicine chairs, there is a possibility of nonresponse bias. Further, relying on chairs to report disabilities in residents may not result in reliable information as they may not be directly involved in the disclosure of disability or the determination of accommodations. However, as departmental leaders, chairs should be apprised on the ongoing diversity efforts. This includes the recruitment of diverse population and training focused on diversity inclusion. Chairs, as leaders, should also be aware of the structures in place to allow for disclosure of disability and the filing of grievances.

Due to the variability of disability disclosure practices, there may be RWDs and FWDs that were not included in reporting by respondents because of existing structures in their departments. Questions in this study contained a list of prescribed options; it is possible that important factors were inadvertently omitted. Additionally, while there are 
Table 4: Active Plan to Recruit Residents With Disabilities ( $\mathbf{N}=71$ )

Number of Faculty With Disabilities

\begin{tabular}{|c|c|c|c|}
\hline \multicolumn{4}{|c|}{ Number of Faculty With Disabilities } \\
\hline & No Faculty With Disabilities & One or More Faculty With Disabilities & Total \\
\hline Yes & $0(0 \%)$ & $4(7 \%)$ & 4 \\
\hline No & $38(71 \%)$ & $12(22 \%)$ & 50 \\
\hline Total & 38 & 16 & 54 \\
\hline Odds ratio: 1.333 & Degrees of freedom: 1 & \multicolumn{2}{|l|}{$P$ value $=.006$} \\
\hline \multicolumn{4}{|c|}{ Community Size } \\
\hline & Urban & Rural & Total \\
\hline Yes & $5(9 \%)$ & $0(0 \%)$ & 5 \\
\hline No & $42(76 \%)$ & $8(15 \%)$ & 50 \\
\hline Total & 47 & 8 & 55 \\
\hline Odds ratio: 1.190 & Degrees of freedom: 1 & \multicolumn{2}{|l|}{$P$ value $=1.000$} \\
\hline \multicolumn{4}{|c|}{ Residency Program Type } \\
\hline & Medical School Based & Community Based & Total \\
\hline Yes & $5(9 \%)$ & $0(0 \%)$ & 5 \\
\hline No & $26(48 \%)$ & $23(43 \%)$ & 49 \\
\hline Total & 31 & 23 & 54 \\
\hline Odds ratio: 0.839 & Degrees of freedom: 1 & \multicolumn{2}{|l|}{$P$ value $=.064$} \\
\hline \multicolumn{4}{|c|}{ Residency Program Region } \\
\hline & North & South & Total \\
\hline Yes & $3(5 \%)$ & $2(4 \%)$ & 5 \\
\hline No & $24(43 \%)$ & $27(48 \%)$ & 51 \\
\hline Total & 27 & 29 & 56 \\
\hline Odds ratio: 1.688 & Degrees of freedom: 1 & \multicolumn{2}{|l|}{$P$ value $=.664$} \\
\hline
\end{tabular}

* Not all respondents answered each question. $\chi^{2}$ and Fisher exact tests were run on cases in which the questions of Active Plan to Recruit Residents With Disabilities and the categorical variable of interest were both answered.

Table 5: Biggest Barrier to Inclusion of Residents With Disabilities ( $N=60$ )

\begin{tabular}{|c|c|c|c|}
\hline \multicolumn{4}{|c|}{ Number of Faculty With Disabilities } \\
\hline Barrier & No Faculty With Disabilities & One or More Faculty With Disabilities & Total \\
\hline Inadequate expertise & $28(48 \%)$ & $10(17 \%)$ & 38 \\
\hline Cost/resources & $15(26 \%)$ & $5(9 \%)$ & 20 \\
\hline Total & 43 & 15 & 58 \\
\hline Odds ratio: 0.933 & Degrees of freedom: 1 & \multicolumn{2}{|l|}{$P$ value $=1.000$} \\
\hline \multicolumn{4}{|c|}{ Community Size } \\
\hline Barrier & Urban & Rural & Total \\
\hline Inadequate expertise & $33(56 \%)$ & $6(10 \%)$ & 39 \\
\hline Cost/resources & $18(31 \%)$ & $2(3 \%)$ & 20 \\
\hline Total & 51 & 8 & 59 \\
\hline Odds ratio: 1.636 & Degrees of freedom: 1 & \multicolumn{2}{|l|}{$P$ value $=.704$} \\
\hline \multicolumn{4}{|c|}{ Residency Program Type } \\
\hline Barrier & Medical School Based & Community Based & Total \\
\hline Inadequate expertise & $21(36 \%)$ & $17(30 \%)$ & 38 \\
\hline Cost/resources & $10(17 \%)$ & $10(17 \%)$ & 20 \\
\hline Total & 31 & 27 & 58 \\
\hline Odds ratio: 1.235 & Degrees of freedom: 1 & \multicolumn{2}{|l|}{$P$ value $=.785$} \\
\hline
\end{tabular}


Table 5: Continued

\begin{tabular}{|l|c|c|c|}
\hline \multicolumn{4}{|c|}{ Residency Program Region } \\
\hline Barrier & North & South & Total \\
\hline Inadequate expertise & $20(33 \%)$ & $20(34 \%)$ & 40 \\
\hline Cost/resources & $9(15 \%)$ & $11(18 \%)$ & 20 \\
\hline Total & 29 & 31 & 60 \\
\hline Odds ratio: 1.222 & Degrees of freedom: 1 & $P$ value $=.788$ \\
\hline
\end{tabular}

* Not all respondents answered each question. $\chi^{2}$ and Fisher exact tests were run on cases in which the questions of the Biggest Barrier to Inclusion of RWDs and the categorical variable of interest were both answered.

definitions of disability outlined in governing bodies, both federal and in the medical field, the ADA definition used in this study may have differed from those of the respondents' personal and organizational definitions. This may have resulted in different inclusion and exclusion criteria and impacted reporting of the prevalence of RWDs and FWDs.

\section{Conclusion}

Family medicine chairs are critical leaders in family medicine, and more broadly in medicine's goal for a diverse physician workforce. Therefore, their support for residents and faculty with disabilities is paramount to creating the opportunities that will generate a physician population that aligns with the population served. As noted in our findings, programs reporting FWD were more likely to have plans to recruit RWD, while the largest perceived barrier to the inclusion of RWD was inadequate expertise. Therefore, we endorse additional opportunities for faculty development that highlight existing guidance on best practices for the inclusion of residents with disabilities, ${ }^{7,21}$ ACGME mandates on disability and diversity inclusion, ${ }^{8-10}$ and literature that shows successful integration of resident accommodations. ${ }^{22,23}$ Actionable and specific goals to include disability must be created if family medicine programs seek to improve their diversity efforts with regard to disabled residents.
FINANCIAL DISCLOSURES: This work is supported by the Health Resources and Services Administration (HRSA) of the US Department of Health and Human Services (HHS) as part of an award totaling $\$ 3,791,026$ with $0 \%$ financed with non-governmental sources. The contents are those of the author(s) and do not necessarily represent the official views of, nor an endorsement, by HRSA, HHS or the US government. For more information, please visit HRSA.gov.

CORRESPONDING AUTHOR: Address correspondence to Dr Lisa M. Meeks, 1018 Fuller Street, Ann Arbor, MI 48104 meeksli@med.umich.edu.

\section{References}

1. World Health Organization (WHO) and World Bank. Summary: World Report on Disability. Geneva, Switzerland: WHO; 2011. http://apps. who.int/iris/bitstream/10665/70670/1/WHO NMH_VIP_11.01_eng.pdf. Accessed March 11, 2021

2. Americans with Disabilities Act of 1990, 42 USC $\S \S 12101$ et seq. https://www.ada.gov/ pubs/adastatute08.htm. Accessed March 11 2021.

3. Nivet MA. A diversity 3.0 update: are we moving the needle enough? Acad Med. 2015;90(12):1591-1593. doi:10.1097/ ACM.0000000000000950

4. Nivet MA, Castillo-Page L, Schoolcraft Conrad S. A diversity and inclusion framework for medical education. Acad Med. 2016;91(7):1031. doi:10.1097/ACM.0000000000001120

5. Gonzaga AMR, Appiah-Pippim J, Onumah CM, Yialamas MA. A framework for inclusive graduate medical education recruitment strategies: meeting the ACGME standard for a diverse and inclusive workforce. Acad Med. 2020;95(5):710-716. doi:10.1097/ ACM.0000000000003073

6. Meeks LM, Herzer K, Jain NR. Removing barriers and facilitating access: increasing the number of physicians with disabilities. Acad Med. 2018;93(4):540-543. doi:10.1097/ ACM.0000000000002112

7. Meeks L, Jain NR. Accessibility, inclusion, and action in medical education: lived experiences of learners and physicians with disabilities. Association of American Medical Colleges; 2018.
8. Accreditation Council for Graduate Medical Education. ACGME Common Program Requirements (Residency). June 10, 2018. https:// www.acgme.org/Portals/0/PFAssets/ProgramRequirements/CPRResidency2019-TCC.pdf. Updated 2019. Accessed March 11, 2021.

9. Accreditation Council for Graduate Medical Education. ACGME Institutional Requirements 8 IV.H.4. Accommodation for Disabilities: The Sponsoring institution must have a policy, not necessarily GME-specific, regarding accommodations for disabilities consistent with all applicable laws and regulations. https:// www.acgme.org/Portals/0/PFAssets/ProgramRequirements/800_InstitutionalRequirements_2021.pdf?ver=2021-02-19-090632-820. Revised February 7, 2021. Accessed March 11, 2021.

10. Accreditation Council for Graduate Medical Education. ACGME Common Program Requirements I.D.2.e. Accommodations for residents with disabilities consistent with the sponsoring institution's policy. https://www. acgme.org/Portals/0/PFAssets/ProgramRequirements/CPRResidencyImplementationTable.pdf. Published 2018. Accessed March 11, 2021.

11. Churgay CA, Smith MA, Woodard L, Wallace LS. A survey of family medicine department chairs about faculty with disabilities. Fam Med. 2015;47(10):776-781.

12. Takakuwa KM, Ernst AA, Weiss SJ. Residents with disabilities: a national survey of directors of emergency medicine residency programs. South Med J. 2002;95(4):436-440. doi:10.1097/00007611-200295040-00013

13. ADA Amendments Act of 2008, 42 USC $\S 2302$ note (2011)

14. Sapp RW, Sebok-Syer SS, Gisondi MA, Rotoli JM, Backster A, McClure Poffenberger C. The prevalence of disability health training and residents with disabilities in emergency medicine residency programs. AEM Education and Training.

15. Meeks LM, Taylor N, Case B, et al. The unexamined diversity: disability policies and practices in US Graduate Medical Education Programs. J Grad Med Educ. 2020;12(5):615619. doi:10.4300/JGME-D-19-00940.1

16. Meeks LM, Herzer KR. Prevalence of selfdisclosed disability among medical students in US allopathic medical schools. JAMA. 2016;316(21):2271-2272. doi:10.1001/ jama.2016.10544 
17. Meeks LM, Case B, Herzer K, Plegue M, Swenor BK. Change in Prevalence of Disabilities and Accommodation Practices Among US Medical Schools, 2016 vs 2019. JAMA. 2019;322(20):2022-2024. doi:10.1001/ jama.2019.15372

18. Meeks LM, Case B, Plegue M, Moreland CJ, Jain S, Taylor N. National prevalence of disability and clinical accommodations in medical education. J Med Educ Curric Dev. 2020;7:2382120520965249. doi:10.1177/2382120520965249

19. Mainous AG III, Seehusen D, Shokar N. CAFM Educational Research Alliance (CERA) 2011 Residency Director survey: background, methods, and respondent characteristics. Fam Med. 2012;44(10):691-693. for the broader CERA methods.
20. Pettigrew TF. Intergroup contact theory. Annu Rev Psychol. 1998;49(1):65-85. doi:10.1146/annurev.psych.49.1.65

21. Meeks LM, Jain NR, Moreland C, Taylor N, Brookman JC, Fitzsimons M. Realizing diverse and inclusive workforce: equal access for residents with disabilities. J Grad Med Educ. 2019;11(5):498-503. doi:10.4300/JGMED-19-00286.1

22. Elliott HW, Arnold EM, Brenes GA, Silvia L, Rosenquist PB. Attention deficit hyperactivity disorder accommodations for psychiatry residents. Acad Psychiatry. 2007;31(4):290-296. doi:10.1176/appi.ap.31.4.290
23. Fitzsimons MG, Brookman JC, Arnholz $\mathrm{SH}$, Baker K. Attention-deficit/hyperactivity disorder and successful completion of anesthesia residency: A case report. Acad Med. 2016;91(2):210-214. doi:10.1097/ ACM.0000000000000854 